\title{
STUDYING THE EFFECT OF DIFFERENT GELLING AGENT ON THE PREPARATION AND CHARACTERIZATION OF METRONIDAZOLE AS TOPICAL EMULGEL
}

\author{
NOOR M DAOOD, ZAINAB E JASSIM*, MOWAFAQ M. GHAREEB AND HIBA ZEKI
}

Department of Pharmaceutics, College of Pharmacy, University of Baghdad, Baghdad, Iraq. Email: zainabeassa@yahoo.com Received: 09 January 2019, Revised and Accepted: 17 January 2019

\section{ABSTRACT}

Objective: Emulgels as topical dosage form recently gains an interest represent a combination of gels and emulsions in united form. Metronidazole is an antimicrobial and anti-inflammatory drug, as the first topical therapy approved for rosacea; metronidazole has remained a cornerstone of rosacea management.

Methods: Emulgel formulations of metronidazole benzoate were prepared using two types of gelling agents, Carbopol 940 and hydroxypropyl methylcellulose, the influence of type and concentration of them on the release of metronidazole benzoate was investigated. The prepared formulations were evaluated on the basis of $\mathrm{pH}$, spreadability, viscosity, drug content, in vitro release, and compatibility studies.

Results: All the prepared emulgels showed acceptable physical properties concerning color, homogeneity, consistency, spreadability, and pH value.

Conclusion: The best formulation (F4) prepared using Carbopol 940 as gelling agent showed the highest drug release through 5 h.

Keywords: Metronidazole benzoate, Emulgel, Carbopol 940, Hydroxypropyl methylcellulose.

(C) 2019 The Authors. Published by Innovare Academic Sciences Pvt Ltd. This is an open access article under the CC BY license (http://creativecommons. org/licenses/by/4. 0/) DOI: http://dx.doi.org/10.22159/ajpcr.2019.v12i3.31504

\section{INTRODUCTION}

Topical drug administration is the simplest and easiest route of localized drug delivery anywhere in the body by routes as ophthalmic, rectal, vaginal, and skin [1]. Topical drug delivery systems are such system in which direct application of a formulation containing an active pharmaceutical ingredient to the skin to obtain the localizing effect of the drug [2]. Delivery of drugs to the skin is an effective and targeted therapy for local dermatological disorders. This route of drug delivery has gained popularity because it avoids first-pass effects, gastrointestinal irritation, and metabolic degradation associated with oral administration, drugs applied to the skin for their local action include antiseptics, antifungal agent, skin emollients, and protectants [3]. Emulgel is an emulsion, either of the oil in water or water in oil type, which is gelled by mixing with a gelling agent [4]. The main advantage of the emulgel that lipophilic drugs can be easily formulated as emulgels. Due to solubility problems, most of the lipophilic drugs cannot be formulated directly as a hydrogel. For this reason, emulgel provides better stability and release of the lipophilic drug in comparison with simple hydrogel base [5].

Metronidazole, which is a synthetic nitroimidazole derivative with antimicrobial and anti-inflammatory properties, has been reported to be effective in the treatment of rosacea through not only topical application but also systemic administration. As the first topical therapy approved for rosacea, metronidazole has remained a cornerstone of rosacea management.

Topical application of metronidazole was shown to be as effective as systemic antibiotic therapy. Metronidazole is particularly effective against papules and pustules and is a well-tolerated alternative to oral antibacterial. The exact mechanism by which topical metronidazole reduces inflammatory lesions and erythema in rosacea is unknown; it is suggested that its anti-inflammatory effect may be due to its antioxidant action [6]. Chemically metronidazole benzoate is 2-(2-methyl-5-nitro1Himidazole-1-yl) ethyl benzoate (Fig. 1), belonging to the category of the antiprotozoal drug [7].
The aim of this work was to develop an emulgel formulation of metronidazole benzoate using hydroxypropyl methylcellulose (HPMC) and Carbopol 940 as gelling agents. The influence of the gelling agent type and concentration was investigated. The rheological studies, spreading coefficient studies, $\mathrm{pH}$, drug content, and in vitro drug release of the prepared emulgels were evaluated.

\section{MATERIALS AND METHODS}

Materials

Metronidazole benzoate was purchased from Lab Depot Inc., USA, HPMC, Carbopol 940 from HiMedia, India, liquid paraffin (Solvochem, UK). Spans 20 and Tween 20 were obtained from Merck Germany. All other chemicals were of analytical reagent grade.

\section{Methods}

Determination of $\lambda_{\max }$ of metronidazole benzoate

Ultraviolet (UV)-Visible spectral analysis of metronidazole benzoate was done using a cary double beam UV-Visible spectrophotometer. Accurately weighed $50 \mathrm{mg}$ of drug was dissolved in $10 \mathrm{ml}$ of ethanol and transferred to $100 \mathrm{ml}$ volumetric flask and the volume was completed with buffer pH 5.5 to form a stock solution $0.5 \mathrm{mg} / \mathrm{ml}$. The absorbance was measured between the wave-length of 200 and $400 \mathrm{~nm}$.

\section{Calibration curve of metronidazole benzoate}

Calibration curve of metronidazole benzoate in buffer $\mathrm{pH} 5.5$ was obtained by preparing serial dilutions from a stock solution $(0.5 \mathrm{mg} / \mathrm{ml})$. Moreover, the samples were analyzed spectrophotometrically at their lambda maximum $319 \mathrm{~nm}$. The absorbance of each sample was plotted versus concentrations.

\section{Optimization of the concentration of emulsifying agent}

The concentration of emulsifying agent and oil phase was optimized by performing a preliminary trial of an emulsion as in Table 1. 


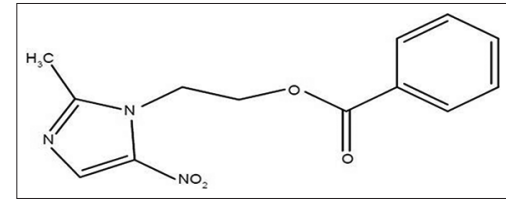

Fig. 1: Chemical structure of metronidazole benzoate

Table 1: Composition of metronidazole benzoate emulsion

\begin{tabular}{llll}
\hline Materials (g) & F1 & F2 & F3 \\
\hline Drug & 1 & 1 & 1 \\
Liquid paraffin & 5 & 5 & 5 \\
Span 20 & 2 & 2.5 & 3 \\
Tween 20 & 2 & 1.5 & 1 \\
Propylene glycol & 5 & 5 & 5 \\
Methylparaben & 0.15 & 0.15 & 0.15 \\
water & 36 & 36 & 36 \\
\hline
\end{tabular}

Table 2: Composition of metronidazole benzoate emulgel

\begin{tabular}{lllllll}
\hline Materials (g) & F1 & F2 & F3 & F4 & F5 & F6 \\
\hline Drug & 1 & 1 & 1 & 1 & 1 & 1 \\
Liquid paraffin & 5 & 5 & 5 & 5 & 5 & 5 \\
Span 20 & 3 & 3 & 3 & 3 & 3 & 3 \\
Tween 20 & 1 & 1 & 1 & 1 & 1 & 1 \\
Propylene glycol & 5 & 5 & 5 & 5 & 5 & 5 \\
Methylparaben & 0.15 & 0.15 & 0.15 & 0.15 & 0.15 & 0.15 \\
HPMC & 1 & 2 & 3 & & & \\
Carbopol 940 & -- & -- & -- & 0.5 & 1 & 1.5 \\
Water up to 100 g & q.s & q.s & q.s & q.s & q.s & q.s \\
\hline
\end{tabular}

HPMC: Hydroxypropyl methylcellulose

Three different formulas of metronidazole benzoate emulsion were prepared using a different concentration of emulsifying agents, at a ratio (1:1), (1:1.66), and (3:1) of span 20 and tween 20 , respectively. The selection of suitable emulsion depends on parameters such as appearance, phase separation, and oil globule formation at the time of emulsion formation. From considering these parameters, F3 containing emulsifying agent at a ratio (3:1) showed good oil globule formation, milkiness, and longer phase separation.

\section{Preparation of metronidazole benzoate emulsion}

The oil phase of the emulsion was prepared by dissolving span 20 in liquid paraffin while the aqueous phase was prepared by dissolving tween 20 in purified water. Methylparaben was dissolved in propylene glycol whereas drug was dissolved in methanol and both solutions mixed with the aqueous phase. Both the oily and aqueous phases were separately heated at $70-80^{\circ} \mathrm{C}$, respectively, then the aqueous phase was added to the oily phase with continuous stirring until it got cooled to room temperature [8].

\section{Preparation of metronidazole benzoate emulgel}

The gel was prepared by dispersing Carbopol 940 in purified water with constant stirring and adjusted the $\mathrm{pH}$ to 6-6.5 using triethanolamine, HPMC was dispersed in purified water and kept overnight. The formulated emulsion was mixed with the gel in 1:1 ratio with gentle stirring to obtain the emulgel. The composition of different formulations has been demonstrated in Table 2 .

Propylene glycol is added to the formulae as a humectant, to increase the spreadability; furthermore, it increases the esthetic benefits regarding of skin feel of the product.

\section{Characterization of metronidazole benzoate Emulgel Physical appearance}

The prepared emulgel formulations were inspected visually for their color, homogeneity, consistency, grittiness, and phase separation [9].

\section{Measurement of $\mathrm{pH}$}

The $\mathrm{pH}$ of emulgel formulations was determined using digital $\mathrm{pH}$ meter at room temperature $\left(25 \pm 1^{\circ} \mathrm{C}\right)$ after $24 \mathrm{~h}$ without dilution. Measurements were taken in triplicates [10].

\section{Rheology}

The viscosity of the formulated batches was determined using a Myr VR 3000 viscometer with spindle 7, 6, and 5. The formulation whose viscosity was to be determined was placed in the beaker and was allowed to settle down for $30 \mathrm{~min}$ at room temperature before the measurement was taken. The spindle was lowered into the center of emulgel taking care that spindle did not touch the bottom of the beaker and rotated at a speed of $2,2.5,3,4,5,6,10,12,20$, and $30 \mathrm{rpm}$. The viscosity reading was noted down and the averages of three readings were taken [11].

\section{Determination of spreadability}

A sample of $(1 \mathrm{~g})$ of each formula was pressed between two slides with $500 \mathrm{~g}$ weight and left for about ( $5 \mathrm{~min}$ ) where no more spreading was expected. Diameters of spread circles were measured in $\mathrm{cm}$ and were taken as comparative values for spreadability. The results obtained are the average of three determinations [12].

\section{Determination of drug content in the emulgel formulas}

Drug content in the emulgel was determined by taking $1 \mathrm{~g}$ of the prepared emulgel which is equivalent to $100 \mathrm{mg}$ of metronidazole benzoate and transferred to $100 \mathrm{ml}$ volumetric flask containing methanol then sonicated and filtered through a filter paper ( $0.45 \mu \mathrm{m}$, Millipore), then suitably diluted and analyzed using UV-visible spectrophotometer at $\lambda_{\max } 319 \mathrm{~nm}$ using phosphate buffer (pH 5.5) as blank [13]

\section{In vitro drug release studies}

A glass cup with a cross-sectional area of $7.5 \mathrm{~cm}^{2}$ was filled with $1 \mathrm{~g}$ of the emulgel, covered with a cellulose membrane, sealed with a rubber band, and inverted under the surface of $900 \mathrm{~mL}$ of phosphate buffer of pH 5.5 at $37 \pm 0.5^{\circ} \mathrm{C}$ in a United States Pharmacopeia dissolution tester with a paddle speed of $50 \mathrm{rpm}$. Aliquots were withdrawn at specified time intervals over $5 \mathrm{~h}$ period and immediately replaced with fresh dissolution medium. The drug content in the withdrawn samples was determined spectrophotometrically at $319 \mathrm{~nm}$ using a UV spectrophotometer (Cary, Australia) [14].

\section{Fourier transforms infrared (FTIR) spectroscopy}

The infrared spectra of metronidazole benzoate, Carbopol 940 and physical mixture of drug and Carbopol 940 (1:1) were recorded between 400 and $4000 \mathrm{~cm}^{-1}$ to detect the drug-excipients interactions. The FTIR spectra for the test samples were obtained using $\mathrm{KBr}$ disk method using an FTIR spectrometer (Lambda scientific 7600, Australia). The resultant spectra were compared for any possible changes in the peaks of the spectra [15].

\section{Differential scanning calorimetry (DSC)}

Thermal analysis of metronidazole benzoate, Carbopol 940 and the physical mixture of drug and Carbopol 940 (1:1) was carried out using a Differential Scanning Calorimeter (Shimadzu DSC-60, Japan). Samples were placed in hermetically sealed aluminum pans. The temperature range tested was $25-300^{\circ} \mathrm{C}$. Samples were heated at $10^{\circ} \mathrm{C} / \mathrm{min}$ under a nitrogen atmosphere at a flow rate of $100 \mathrm{ml} / \mathrm{min}$ [16].

\section{Photomicrography}

Morphology of emulgel was studied under the light microscope. Optimized batches of the emulgel were viewed under a light microscope to study their shape. The emulgel was suitably diluted, mounted on a glass slide and viewed by the light microscope under magnification of $\times 10$ [17].

\section{Statistical analysis}

The studies have been done in triplicate; the data represent the mean \pm standard deviation. The statistical analysis was performed using 


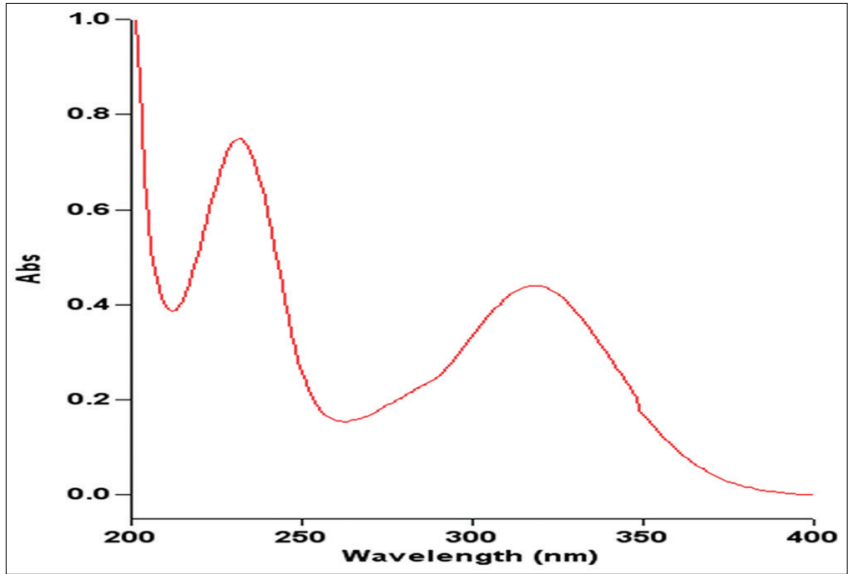

Fig. 2: Ultraviolet scan of metronidazole benzoate in phosphate buffer pH 5.5

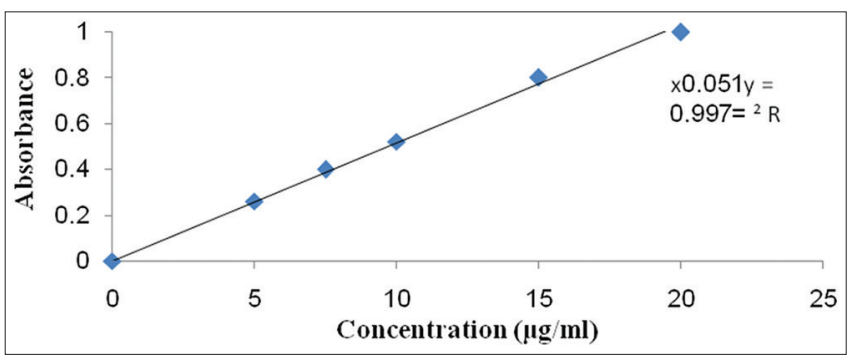

Fig. 3: Calibration curve of metronidazole benzoate in phosphate buffer solution pH 5.5

Table 3: Physical characteristics of prepared metronidazole benzoate emulgel

\begin{tabular}{lllll}
\hline Formula & Color & Homogeneity & Phase separation & $\mathbf{p H}^{*}$ \\
\hline F1 & Off-white & Excellent & No & $5.61 \pm 0.015$ \\
F2 & Off-white & Excellent & No & $5.56 \pm 0.09$ \\
F3 & Off-white & Excellent & No & $5.4 \pm 0.015$ \\
F4 & White & Excellent & No & $7.04 \pm 0.81$ \\
F5 & White & Excellent & No & $6.25 \pm 0.05$ \\
F6 & White & Excellent & No & $6.27 \pm 0.19$ \\
\hline
\end{tabular}

"Mean \pm SD, n=3. SD: Standard deviation

student's t-test. A difference below the probability level was considered as statistically significant $(\mathrm{p}<0.05)$.

\section{RESULTS AND DISCUSSION}

\section{Determination of $\lambda_{\max }$ of metronidazole benzoate}

Scanning of metronidazole benzoate stock solution $(0.5 \mathrm{mg} / \mathrm{ml})$ in phosphate buffer (pH 5.5) by UV spectrophotometer at $200-400 \mathrm{~nm}$ gave the spectrum shown in Fig. 2. The maximum absorbance $\left(\lambda_{\max }\right)$ found to be $319 \mathrm{~nm}$, which is similar to standard references [18]

\section{Calibration curve of metronidazole benzoate}

Fig. 3 shows the calibration curve of metronidazole benzoate in phosphate buffer ( $\mathrm{pH}$ 5.5); a straight line was obtained by plotting the absorbance versus concentration. This indicates that the calibration curve within this range of concentration obeys Beer-Lamberts law at $\lambda_{\max } 319 \mathrm{~nm}$.

\section{Physical appearance}

Total six formulas of emulgel were prepared; emulgel formulations prepared with HPMC were off-white, while the formulations prepared using Carbopol 940 were white. All the formulas were viscous, creamy preparation with a smooth, homogeneous texture, and glossy appearance. Results have been discussed in Table 3.

\section{Measurement of $\mathrm{pH}$}

The $\mathrm{pH}$ of the emulgel formulations was in the range of 5.4 $\pm 0.015-$ $7.04 \pm 0.81$ as shown in Table 3, which lies in the normal pH range of the skin and would not fabricate any skin irritation.

\section{Rheology}

Rheological behavior of the emulgel formulations exhibited nonNewtonian shear thinning pseudoplastic type of flow, i.e., decreases in viscosity at increasing shear rates. As the shear stress is increased (Fig. 4), the disarranged molecules of the gelling material are caused to align their long axes in the direction of flow. Such orientation reduces the internal resistance of the material and decreases viscosity [19]. The viscosity of the formulations increases as the concentration of polymer increases; F3 that contain 3g of HPMC as the gelling agent did not show the readings on viscometer for the viscosity, and it might be due to the higher concentration of the gelling agent and high consistency.

F4 possessed thixotropic behavior, where the down curve was displaced about the up curve, showing at any rate of shear on the down curve lower shear stress than it had on the up curve; a hysteresis loop was formed between the two curves. Thixotropic, or time-dependent flow, occurs because the gel requires a finite time to rebuild its original structure that breaks down during continuous shear measurements. It is noteworthy that thixotropy is a desirable characteristic of pharmaceutical preparations, both in engineering design and consumer application, to deliver an initially thick product as a thinner, easily spreadable material.

The recorded viscosities of the different emulgel formulations at both low and high shear rates are shown in Fig. 4, which showed that the Carbopol-based formulations (F4, F5, and F6) possessed considerably higher viscosities than the HPMC-based formulations (F1and F2).

\section{Spreadability}

Spreadability of emulgel was measured regarding the diameter of a circle produced. Spreadability test was carried out for all the emulgel formulations as depicted in Fig. 5. The therapeutic efficacy of emulgel depends on its spread. The emulgel spreading helps in the uniform application to the skin, so the prepared formulas must have a good spreadability and satisfy the ideal quality in topical application. Furthermore, this is considered an important factor in patient compliance with treatment [20]. The diameters of the spread circles ranged from $6.9 \mathrm{~cm}$ seen with the emulgel prepared by Carbopol to $8.9 \mathrm{~cm}$ seen with HPMC emulgel. The spreadability of HPMC emulgel was more than Carbopol 940 emulgel and spreadability of the emulgel decreases with the increase in the concentration of the polymer.

\section{Drug content determination}

The drug content in emulgel was found in the range of $90 \pm 1-70 \pm 0.20 \%$, the lower drug content it may be due to the high concentration of liquid paraffin and emulsifying agent [21], and the drug content of all emulgel formulation is given in Fig. 6.

\section{In vitro drug release}

The release of metronidazole benzoate from the prepared emulgels was performed to study the effect of polymers types, concentration and the effect of both emulsifying agent and oil phase on the release of drug aiming to select the best formula.

It was observed that all the formulations had become liquefied and diluted at the end of the experiment, indicating water diffusion through the membrane [22].

The in vitro release profile of metronidazole benzoate from its various emulgel formulations is depicted in Fig.7. In case of Carbopol 940 based formulations, the release of the drug can be ranked in the following descending order: $\mathrm{F} 4>\mathrm{F} 5>\mathrm{F} 6$, where the amounts of the drug release after $5 \mathrm{~h}$ were $9 \%, 6 \%$, and $3 \%$, respectively, while in the case of HPMC-based formulation the release of the drug can be ranked in the 

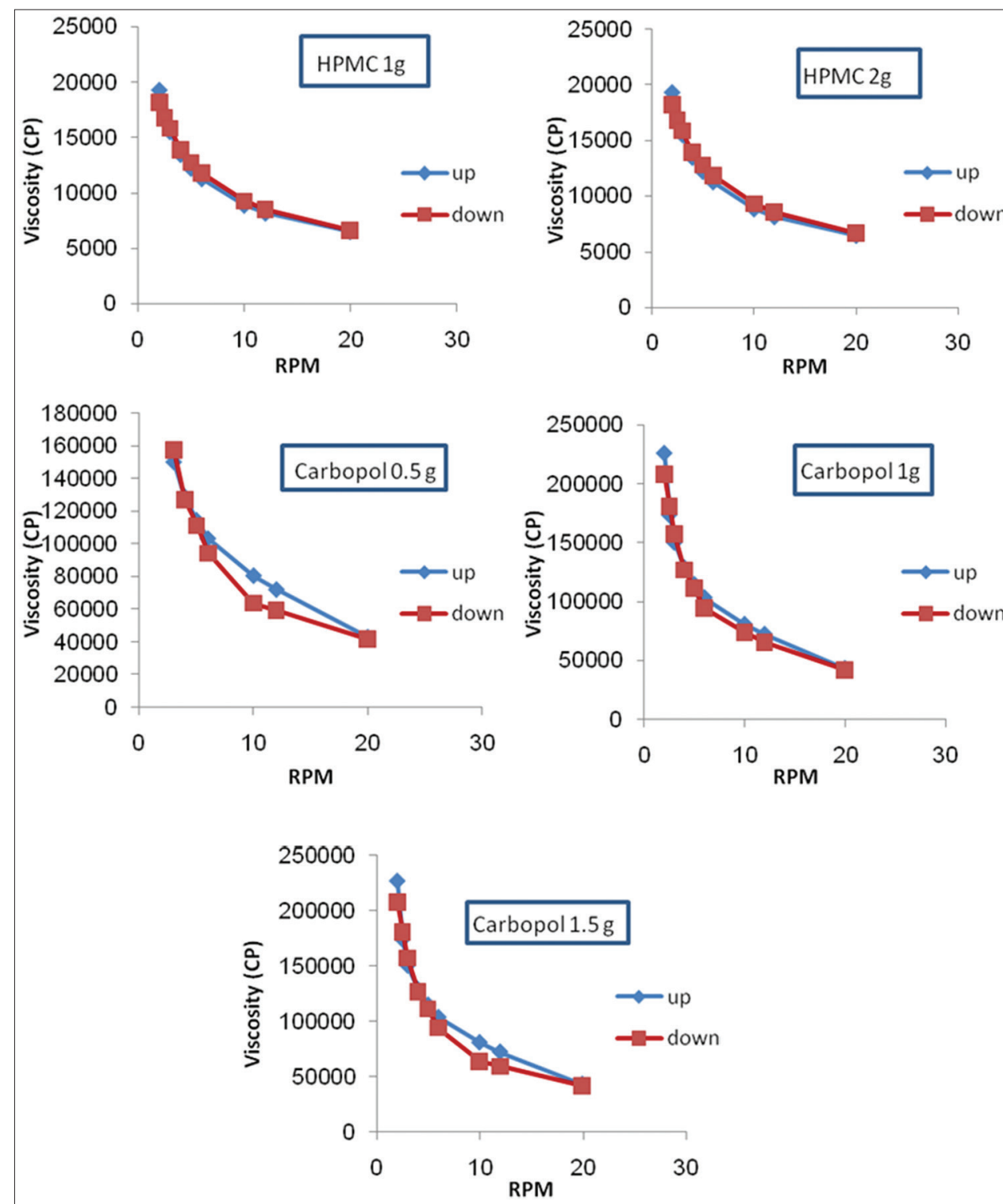

Fig. 4: Rheograms of metronidazole benzoate emulgel formulations (mean \pm standard deviation, $n=3$ )

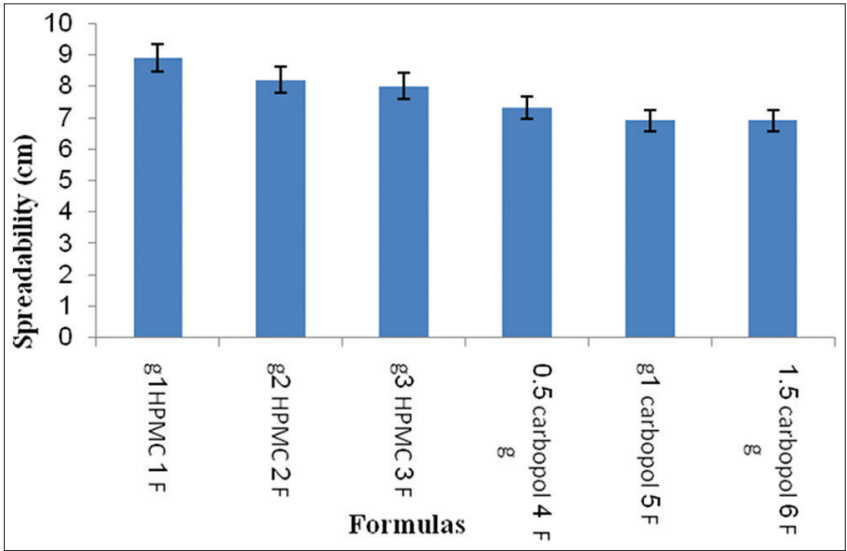

Fig. 5: Spreadability of metronidazole benzoate emulgel (mean \pm standard deviation, $\mathrm{n}=3$ )

following descending order: F1 > F2, where the amounts of the drug release after $5 \mathrm{~h}$ were $1 \%$ and $0.6 \%$, respectively. F3 containing $3 \%$ of HPMC was excluded from dissolution study due to its higher viscosity.

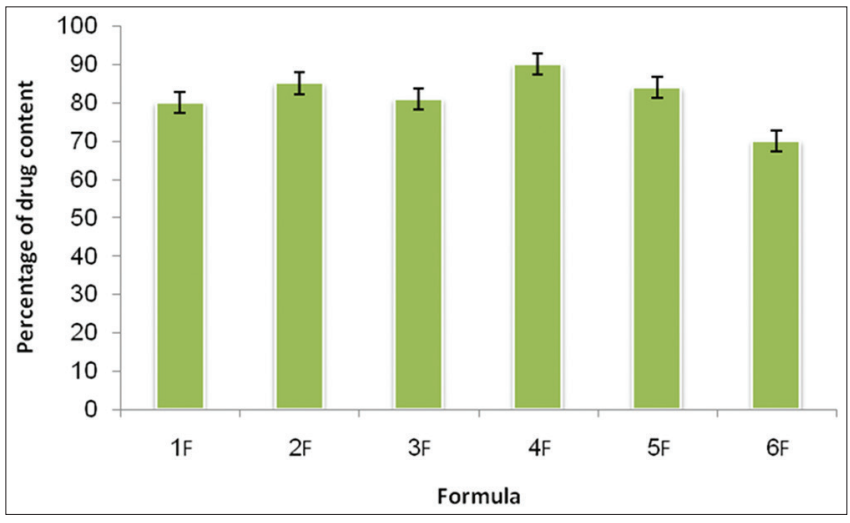

Fig. 6: Comparing of drug content of the various formulation of metronidazole benzoate emulgel (mean \pm standard deviation, $n=3$ )

From these results, it can be concluded that Carbopol 940 based formulations show higher drug release $(\mathrm{p}<0.05)$ in comparison with corresponding HPMC-based formulations. The higher drug release was observed with Carbopol 940 based formulation F4. 
The presence of liquid paraffin leads to retardation of drug release from its emulgel formulation. This finding was in agreement with

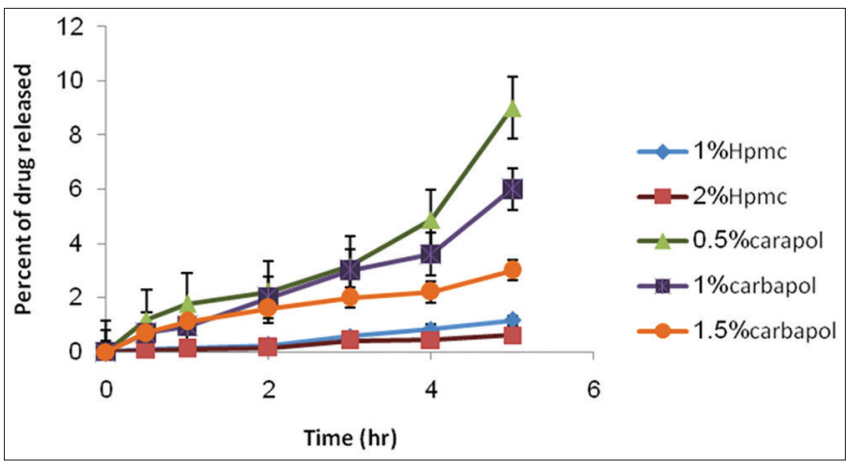

Fig. 7: In vitro drug release profile from emulgel formulations (mean \pm standard deviation; $n=3$ )
El-Bary et al. [23], who proved that the presence of liquid paraffin lead to retardation of chloramphenicol release from its emulgel formulation.

\section{FTIR spectroscopy}

The infrared spectra of metronidazole benzoate, Carbopol 940 and physical mixture of drug and polymer were recorded and shown in Figs. 8-10, respectively.

FTIR spectra of metronidazole benzoate showed the characteristic bands at $1591 \mathrm{~cm}^{-1}, 1583 \mathrm{~cm}^{-1}, 1464.67 \mathrm{~cm}^{-1}, 1451.10 \mathrm{~cm}^{-1}$, and $708.71 \mathrm{~cm}^{-1}$ indicate the presence of the aromatic ring. The ester is characterized by the strong absorption band of the carbonyl $\mathrm{C}=0$ stretching vibration at $1717.30 \mathrm{~cm}^{-1}$ and the control band of the $\mathrm{C}$-0-single-bond vibrations at $1185.04 \mathrm{~cm}^{-1}$. The benzoate ester is characterized by the $\mathrm{C}$ - 0 -group bands at $1267.97 \mathrm{~cm}^{-1}, 1259.83 \mathrm{~cm}^{-1}, 1113.69 \mathrm{~cm}^{-1}$, and $1092.48 \mathrm{~cm}^{-1}$. The aromatic $\mathrm{C}-\mathrm{N}$-stretching vibrations are indicated by absorption bands at $1360.53 \mathrm{~cm}^{-1}$, and the aliphatic $\mathrm{C}-\mathrm{N}$-vibrations show bands at $1065.48 \mathrm{~cm}^{-1}$ and $1024.98 \mathrm{~cm}^{-1}$. The bands at $1523.49 \mathrm{~cm}^{-1}$ and $1360.53 \mathrm{~cm}^{-1}$ indicate the presence of the nitro group [24].

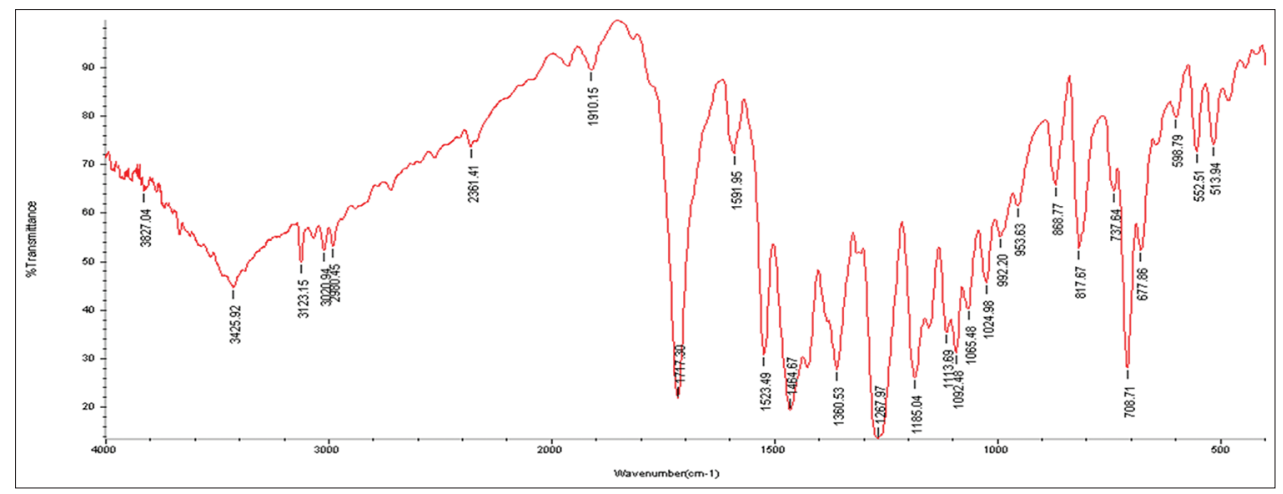

Fig. 8: Four ier transforms infrared spectrum of metronidazole benzoate

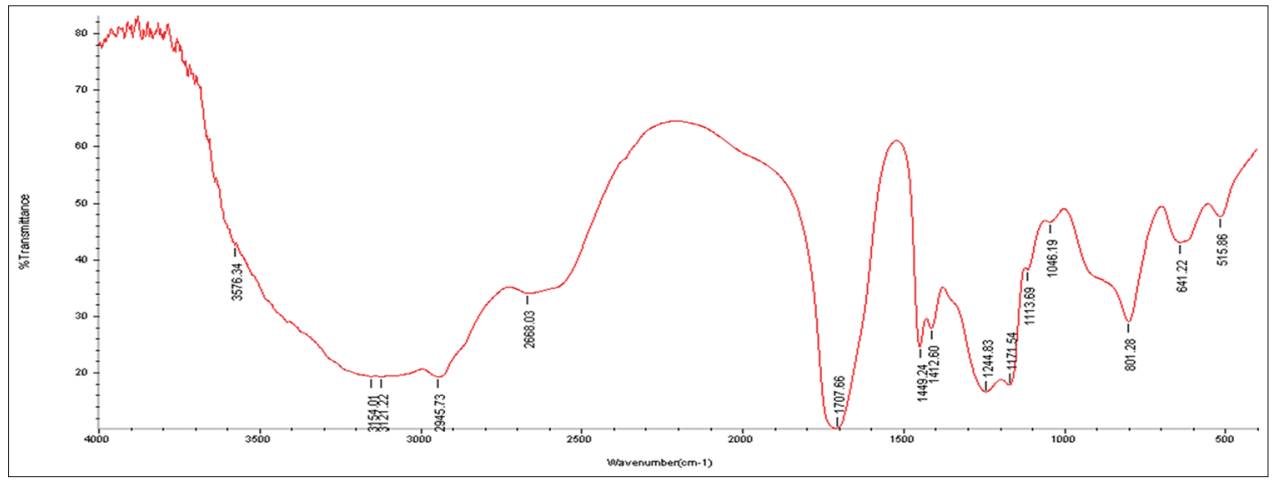

Fig. 9: Fourier transforms infrared spectrum of Carbopol 940

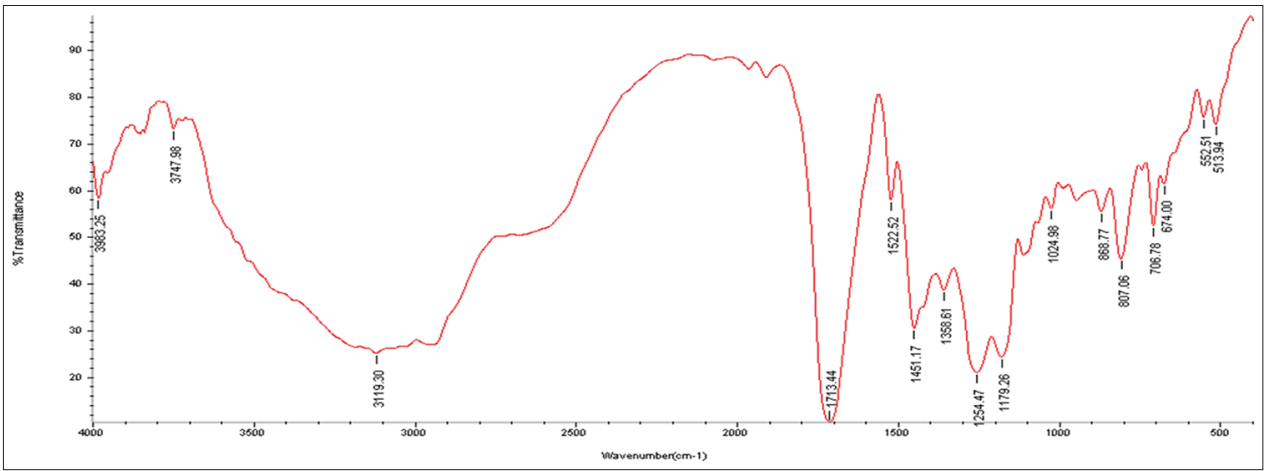

Fig. 10: Fourier transforms infrared spectrum of a physical mixture of drug and Carbopol 940 at a ratio (1:1) 


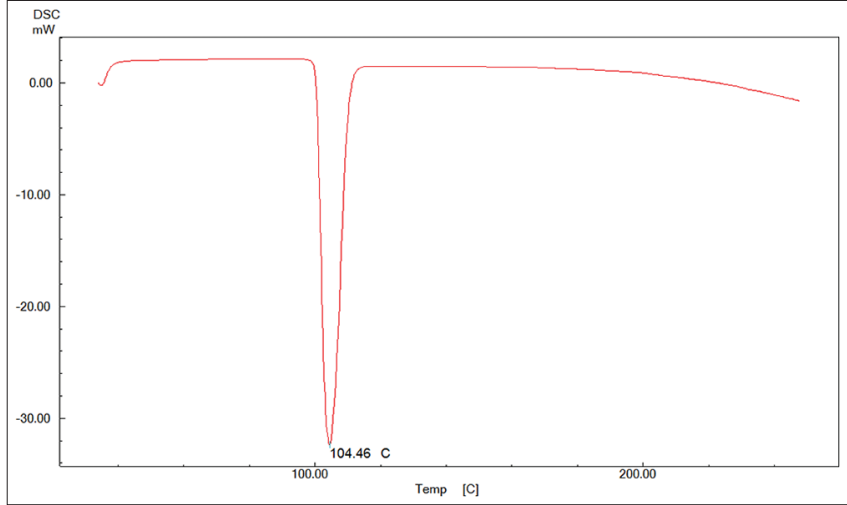

Fig. 11: Differential scanning calorimetry thermogram of metronidazole benzoate

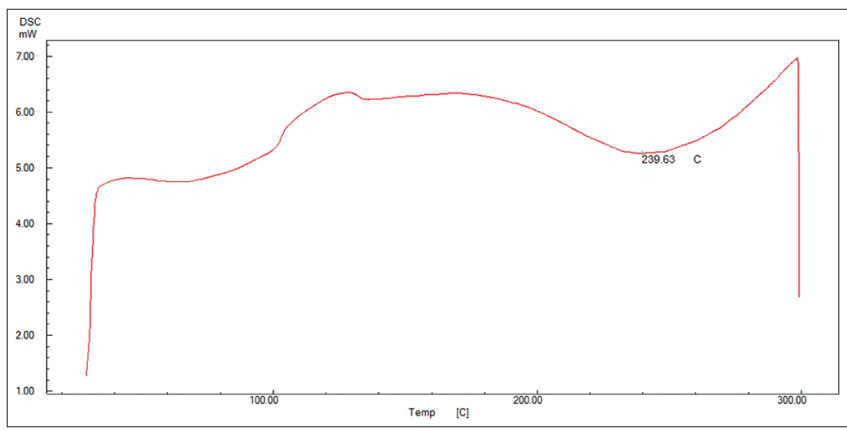

Fig. 12: Differential scanning ca lorimetry thermogram of Carbopol 940

FTIR spectra showed that there were no interactions identified between drug and polymer. From the FTIR spectral analysis, all the principal peaks observed in pure drug were present in the FTIR spectra of the physical mixtures of best formulation since the absorption peaks of the drug still could be detected in the mixture as in Fig. 10.

\section{DSC}

Thermal analysis of metronidazole benzoate, Carbopol 940 and the physical mixture of drug and Carbopol 940 (1:1) was demonstrated in Figs. 11-13, respectively. The thermogram of crystalline metronidazole benzoate showed an endothermic sharp peak at $104^{\circ} \mathrm{C}$ due to the melting temperature of metronidazole benzoate which was consistent with literature value [25]. Carbopol 940 showed two endothermic peaks at $71^{\circ} \mathrm{C}$ and $239^{\circ} \mathrm{C}[26]$. The physical mixture of drug and Carbopol 940 at a ratio (1:1) showed the characteristic peak of metronidazole benzoate, indicating no interaction between drug and polymer.

\section{Photomicrography}

The suitably diluted emulgel of selected formula F4 was observed under the light microscope at $\times 10$ (Fig. 14). From the photomicrograph, nearly spherical globules of emulsion were observed, though this study does not give any exact estimate of size; however, it gives a general idea about the formation of emulsion and success of the method used.

\section{CONCLUSION}

It can be concluded from the above results that metronidazole benzoate emulgel formulations prepared with Carbopol 940 (F4) showed acceptable physical properties, drug content, and drug release which deliver about $9 \%$ of drug within $5 \mathrm{~h}$; thus, it can be suggested as a promising formula to prepare Metronidazole benzoate emulgel for the treatment of rosacea. However, further preclinical and clinical studies are required.

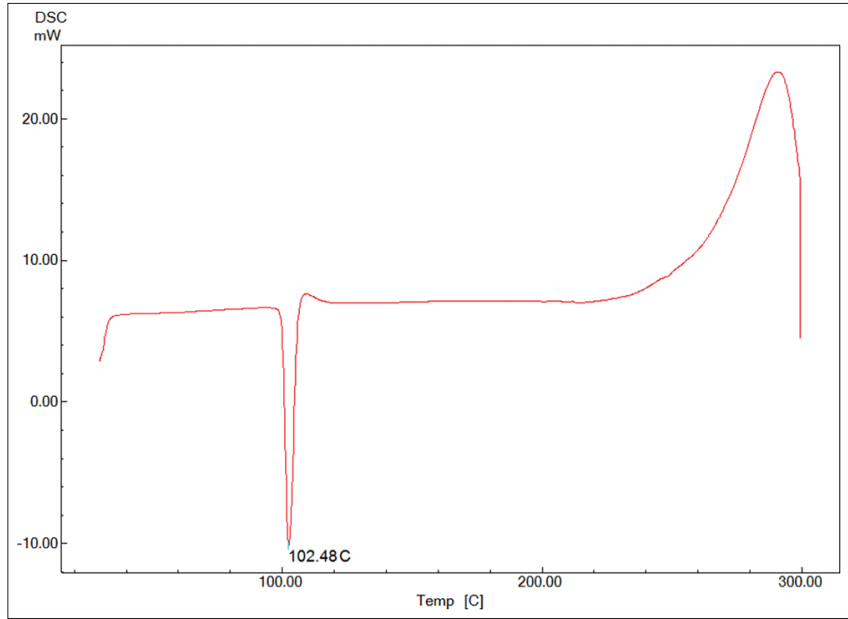

Fig. 13: Differential scanning calorimetry thermogram of the physical mixture of metronidazole benzoate and Carbopol 940 at a ratio (1:1)

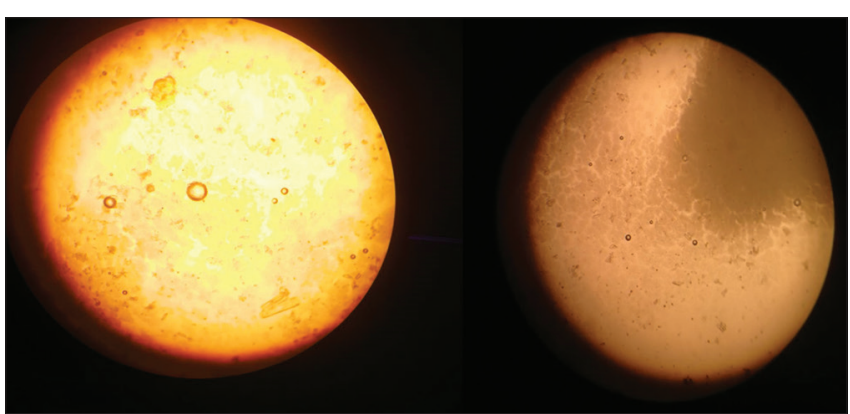

Fig. 14: Photomicrographs of formulation F4

\section{AUTHOR'S CONTRIBUTIONS}

Authors contributed to the design and implementation of the research, to the analysis of the results and the writing of the manuscript.

\section{CONFLICTS OF INTEREST}

Authors declare that they have no conflicts of interest.

\section{REFERENCES}

1. Anu H, Sonali J, Sanjay J. Emulgel: An emergent tool in topical drug delivery. Int J Pharm Sci Res 2014;5:1653-60.

2. Davinder K, Singh J, Antil M, Kumar V. Emulgel-novel topical drug delivery system-a comprehensive review. Int J Pharm Sci Res 2016;7:4733?

3. Japan P, Patel B, Banwait H, Parmar K, Patel M. Formulation and evaluation of topical aceclofenac gel using different gelling agent. Int J Drug Dev Res 2011;3:156-64]

4. Piyusha D, Jain A, Vyas N, Khambete H, Jain S. Gellified emulsion for sustain delivery of itraconazole for topical fungal diseases. Int J Pharm Pharm Sci 2010;2:104-12

5. Khaled MH, Rambo SM, Al-Zahrani MM, Al-Subhi SM, Fahmy UA. Ketoprofen emulgel: Preparation, characterization, and pharmacodynamic evaluation. Int J Pharm Sci Rev Res 2013;20:306-10.

6. Tirnaksiz F, Kayiş A, Çelebi N, Adişen E, Erel A. Preparation and evaluation of topical microemulsion system containing metronidazole for remission in rosacea. Chem Pharm Bull (Tokyo) 2012;60:583-92.

7. Mali A, Hake A, Patil M, Bathe R, Patil M, Tamboli A. Estimation of metronidazole benzoate in bulk and formulation by first order derivative area under curve UV-spectrophotometric methods. Int J Res Pharm Pharm Sci 2016;1:42-6.

8. Devesh K, Vyas RB, Lad C, Patel M, Lal B, Parmar R. Formulation, development and characterization of emulgel of a NSAID'S. Pharm Chem J 2014;1:9-16. 
9. Chavda VP, Patel J, Parmar K, Nakum S, Soniwala MM, Chavda JR. Preparation and evaluation of methyl salicylate counter reparation and evaluation of methyl salicylate counter-irritant emulgel of mefenamic acid irritant emulgel of mefenamic acid. Int J Pharm Med Res 2013;1:27-32.

10. Vijaya B, Vippamakula S, Lakshmi PK. Development and optimization of novel diclo fenacemulgel for topical drug delivery. Int J Compr Pharm 2011;2:1-9.

11. Kumari A, Singh A, Saurabh SS, Rathore KS, Issaranil R. Formulation and evaluation of lycopene emulgel. Indo Am J Pharm Sci 2015;2:1013-27.

12. Doaa AH, El-Rhman DA, Abdel-Halim SA, El-Nabarawi MA. Formulation and evaluation of fluconazole topical gel. Int J Pharm Pharm Sci 2012;4:176-83.

13. Anuradha AS, Mohite SK. Formulation and evaluation of itraconazoleemulgel for topical drug delivery. Asian J Pharm Technol 2015;5:91-6?

14. Mohamed MI. Optimization of chlorphenesin emulgel formulation. AAPS J 2004;6:e26.

15. Ramakanth A, Kumar VS. Formulation and characterization of ketoprofenemulgels. J Appl Pharm Sci 2015;5:112-7.

16. Ulya B, Amasya G, Sen T, Tarimci N. Topical emulgel formulation containing inclusion complex of calcipotriol with cyclodextrin. J Incl Phenom 2014;78:249-55.]

17. Dignesh MK, Ashish DM, Dinesh RS. Formulation design and development of piroxicamemulgel. Int J PharmTech Res 2012;4:1332-44.
18. Theresa CJ, Minju R, Reshma KR, Vidya TV, Vrinda PS, Vrindha TN. Spectrophotometric determination of metronidazole in bulk and dosage form. Int J Pharm Pharm Sci 2014;1:11-5.

19. Kishor VN, Shailesh GS, Moreshwar PP. Formulation development, in vitro and in vivo evaluation of microemulsion-based gel loaded with ketoprofen. Drug Deliv 2015;22:509-15.

20. Dantas MG, Reis SA, Damasceno CM, Rolim LA, Rolim-Neto PJ, Carvalho FO, et al. Development and evaluation of stability of a gel formulation containing the monoterpeneborneol. Sci World J 2016;2016:1-4.

21. Patil SA, Sarode S, Sathe BS, Jain PV, Jain BV, Vadnere GP. Formulation and evaluation of etodolac trans-emulgel. World J Pharm Pharm Sci 2014;3:1731-49

22. Chavda V, Vishal R. Formulation and evaluation of naproxen emulgel for topical delivery by a modified method. Int J Compr Pharm 2013;7:1-4.

23. El-Bary AA, Shalaby S, El-Aal A. Formulation and stability of chloramphenicolgel and emulgel. Bull Fac Pharm 2001;39:89-99.

24. Patil PD, Desai SR, Disouza JI. Stability analysis and quantitative evaluation of metronidazole suspension. Ind J Pharm Bio Res 2016;4:1-5.

25. Alam MA, Al-Jenoobi FI, Al-Mohizea AM, Ali R. Effervescence assisted fusion technique to enhance the solubility of drugs. AAPS PharmSciTech 2015;16:1487-94.

26. Usama FA, Heba FM. Novel pharmaceutical gels containing glycyrrhizic acid ammonium salt for chronic wounds. Br J Pharm Res 2014;4:654. 